\title{
Practice Parameter: Therapies for benign paroxysmal positional vertigo (an evidence-based review)
}

\section{Report of the Quality Standards Subcommittee of the American Academy of Neurology \\ (6) 四}

T.D. Fife, $M D$

D.J. Iverson, $\mathrm{MD}$

T. Lempert, MD

J.M. Furman, MD, $\mathrm{PhD}$

R.W. Baloh, MD

R.J. Tusa, MD, PhD

T.C. Hain, MD

S. Herdman, PT, PhD,

FAPTA

M.J. Morrow, MD

G.S. Gronseth, MD

Address correspondence and reprint requests to the American Academy of Neurology, 1080 Montreal Ave., St. Paul, MN 55116 guidelines@aan.com
INTRODUCTION Benign paroxysmal positional vertigo (BPPV) is a clinical syndrome characterized by brief recurrent episodes of vertigo triggered by changes in head position with respect to gravity. BPPV is the most common cause of recurrent vertigo, with a lifetime prevalence of $2.4 \% .^{1}$

The term BPPV excludes vertigo caused by lesions of the CNS. BPPV results from abnormal stimulation of the cupula within any of the three semicircular canals (figure e-1 on the Neurology ${ }^{\circledR}$ Web site at www.neurology.org); most cases of BPPV affect the posterior canal. The cupular excitatory response is usually related to movement of otoliths (calcium carbonate crystals) that create a current of endolymph within the affected semicircular canal. The most common form of BPPV occurs when otoliths from the macula of the utricle fall into the lumen of the posterior semicircular canal responding to the effect of gravity. These ectopic otoliths, which have been observed intraoperatively, are referred to as canaliths. The canaliths are dense and move in the semicircular canal when the head position is changed with respect to gravity; the canalith movement ultimately deflects the cupula, leading to a burst of vertigo and nystagmus. In some cases, canaliths adhere to the cupula, causing cupulolithiasis, which is a form of BPPV less responsive to treatment maneuvers.

Typical signs of BPPV are evoked when the head is positioned so that the plane of the affected semicircular canal is spatially vertical and thus aligned with gravity. This produces a paroxysm of vertigo and nystagmus after a brief latency. Positioning the head in the opposite direction reverses the direction of the nystagmus. These responses often fatigue upon repeat positioning. The duration, frequency, and intensity of symptoms of BPPV vary, and spontaneous recovery occurs frequently. Table e- 1 outlines the characteristics of BPPV by canal type.

Repositioning maneuvers are believed to treat BPPY by moving the canaliths from the semicircular canal to the vestibule from which they are absorbed. There are a number of repositioning maneuvers in use, but they lack standardization. The figures and Web-based video clips do not include all variations but represent those maneuvers and treatments used in the Class I and Class II studies that are reviewed as well as several others in common use.

This practice parameter seeks to answer the following questions: 1) What maneuvers effectively treat posterior canal BPPV? 2) Which maneuvers are effective for anterior and horizontal canal BPPV? 3) Are postmaneuver restrictions necessary? 4) Is concurrent mastoid vibration important for efficacy of the maneuvers? 5) What is the efficacy of habituation exercises, Brandt-Daroff exercises, or patient self-administered treatment maneuvers? 6) Are medications effective for BPPV? 7) Is surgical occlusion of the posterior canal or singular neurectomy effective for BPPV?
Supplemental data at www.neurology.org

\section{GLOSSARY}

AAN = American Academy of Neurology; BPPV = benign paroxysmal positional vertigo; CONSORT = Consolidated Standards of Reporting Trials; CRP = canalith repositioning procedure; NNT = number needed to treat.

From the Barrow Neurological Institute and University of Arizona College of Medicine (T.D.F.), Phoenix, AZ; Humboldt Neurological Medical Group, Inc. (D.J.I.), Eureka, CA; Department of Neurology (T.L.), Schlosspark-Klinik, Berlin, Germany; Department of Otolaryngology (J.M.F.), University of Pittsburgh, PA; Department of Neurology (R.W.B.), Reed Neurological Research Center, University of California, Los Angeles, CA; Departments of Neurology (R.J.T.) and Rehabilitation Medicine (S.H.), Emory University; Atlanta, GA; Northwestern University (T.C.H.), Chicago, IL; Providence Multiple Sclerosis Center (M.J.M.), Portland, OR; and University of Kansas (G.S.G.), Kansas City, KS.

Approved by the Quality Standards Subcommittee on May 1, 2007; by the Practice Committee on June 21, 2007; and by the American Academy of Neurology Board of Directors in July 2007.

QSS Subcommittee members, AAN classification of evidence, Classification of recommendations, Conflict of Interest Statement, Mission Statement of the QSS, and references e1-e32 are available as supplemental data on the Neurology ${ }^{(B)}$ Web site at www.neurology.org. Disclosure: Author disclosures are provided at the end of the article.

All figures in this manuscript and online were printed with permission from Barrow Neurological Institute. 


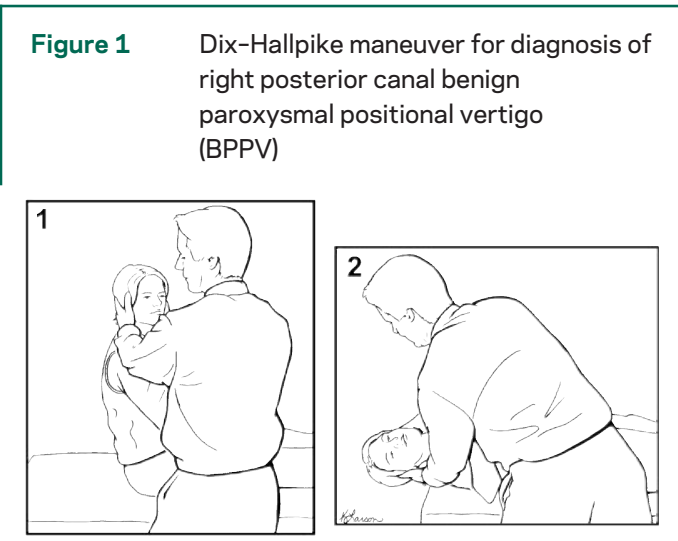

The patient's head is turned 45 degrees toward the side to be tested and then laid back quickly. If BPPV is present, nystagmus ensues usually within seconds.

DESCRIPTION OF THE ANALYTIC PROCESS Otoneurologists with expertise in BPPV and general neurologists with methodologic expertise were invited by the Quality Standards Subcommittee (appendix e-1) to perform this review. Using the four-tiered classification scheme described in appendix e-2, author panelists rated all relevant articles between 1966 and June 2006.

Articles included in this analysis met all of these criteria: 1) BPPV was diagnosed by both symptoms of positional vertigo lasting less than 60 seconds, and paroxysmal positional nystagmus in response to the Dix-Hallpike maneuver (figure 1) or other appropriate provocative maneuver; 2) for all forms of BPPV, the nystagmus was characterized by a brief latency before the onset of nystagmus or a reduction of nystagmus with repeat Dix-Hallpike maneuvers (fatigability); 3) for posterior canal BPPV, a positive Dix-Hallpike maneuver was defined by the presence of upbeating and torsional nystagmus with the top pole of rotation beating toward the affected (downside) ear; and 4) for horizontal canal BPPV, the Dix-Hallpike or supine roll maneuver produced horizontal geotropic (toward the ground) or apogeotropic (away from the ground) directionchanging paroxysmal positional nystagmus. Geotropic direction-changing positional nystagmus refers to paroxysmal right beating nystagmus when the supine head is turned to the right and paroxysmal left beating nystagmus with the supine head turned to the left. Conversely, apogeotropic indicates the nystagmus is right beating with the head turned to the left and left beating with head turned to the right.

ANALYSIS OF EVIDENCE Question 1: What maneuvers effectively treat posterior canal BPPV? Canalith repositioning procedure for BPPV. Of 15 randomized controlled trials identified, there were two Class I studies ${ }^{2,3}$ and three Class II studies. ${ }^{4-6}$
The first Class I study of 36 patients $^{2}$ compared the canalith repositioning procedure (CRP) (figure 2) with a sham maneuver where the patient was placed in a supine position with the affected ear down for 5 minutes and then sat up. All patients were symptomatic for at least 2 months; the median duration of symptoms was 17 months (range 2-240 months) in the treatment group and 4 months (range 2-276 months) in the control group, a difference that approached significance.

At 4 weeks, $61 \%$ of the treated group reported complete symptom resolution, vs $20 \%$ of the sham-treated group ( $p=0.032$ ). The number needed to treat (NNT) was 2.44. The NNT is an epidemiologic measure that indicates the number of patients that had to have treatment to eliminate symptoms in one patient. The Dix-Hallpike maneuver was negative in $88.9 \%$ of treated patients vs $26.7 \%$ in sham-treated patients $(p<$ 0.001 , NNT $=1.60$ ), as measured by an observer blinded to treatment.

The second Class I randomized controlled trial and crossover study, ${ }^{3}$ of 66 patients with a diagnosis of posterior BPPV based on a positive DixHallpike maneuver, compared a CRP (figure 2) with a sham procedure. The sham procedure consisted of a CRP performed on the contralateral, asymptomatic ear.

After 24 hours, $80 \%$ of treated patients were asymptomatic and had no nystagmus with the Dix-Hallpike maneuver compared with $10 \%$ of sham patients $(p<0.001$; NNT $=1.43)$. At this point, all patients in both the treatment and control groups with a persistently positive DixHallpike maneuver underwent a CRP. Ninetythree percent of patients from the original control group reported resolution of symptoms 24 hours after undergoing the CRP. By 1 week, $94 \%$ of patients in the original treatment group and $82 \%$ of patients in the original control group (all of whom underwent a CRP at 24 hours) were asymptomatic ( $p$ value not stated). At 4 weeks, $85 \%$ of patients in both groups were asymptomatic.

Three studies were rated as Class II because the method of allocation concealment was not specified. Allocation concealment is a technique for preventing researchers from inadvertently influencing which patients are assigned to the treatment or placebo group; inadequate allocation concealment may cause selection bias that overestimates the treatment effect. ${ }^{7}$

The first Class II study of 50 patients $^{4}$ compared a CRP with the same sham maneuver performed by Lynn et al., ${ }^{2}$ with blinded outcome measurements of symptom resolution and absent 
Figure 2 Canalith repositioning procedure for right-sided benign paroxysmal positional vertigo
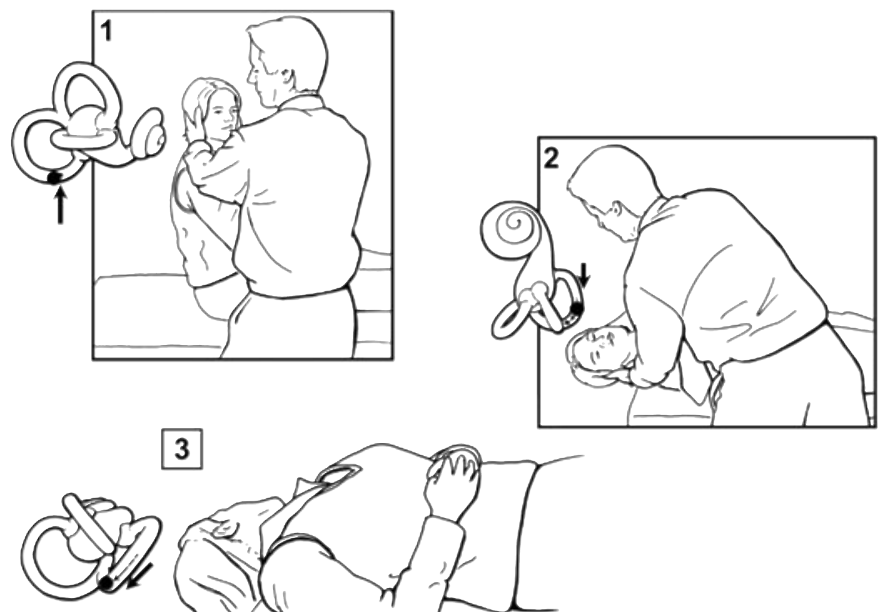

3

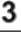

II

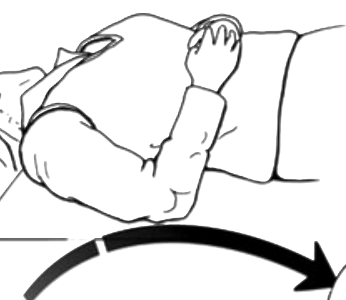

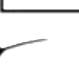
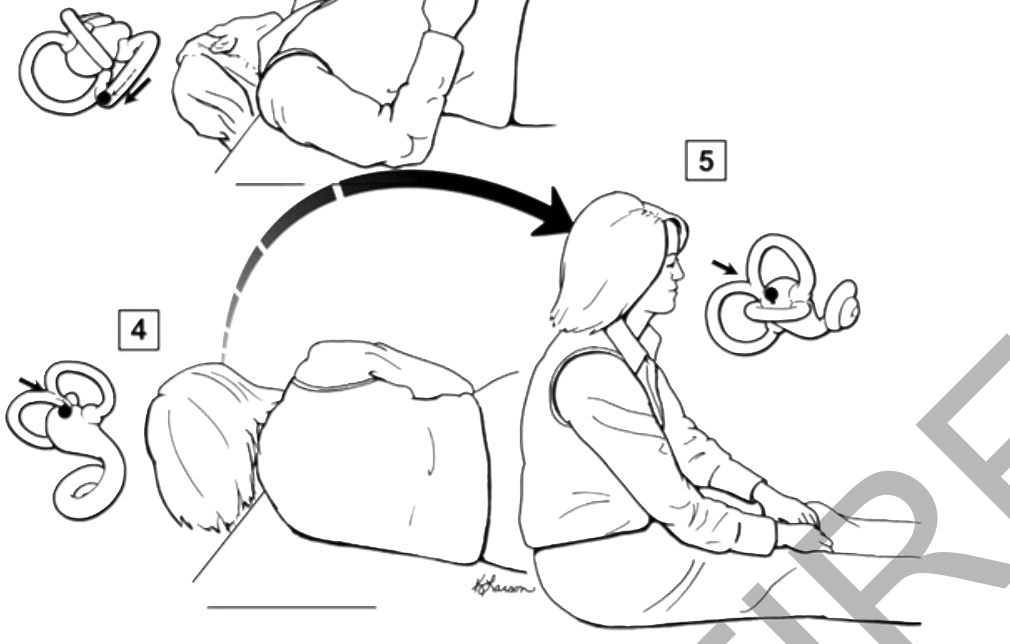

Steps 1 and 2 are identical to the Dix-Hallpike maneuver. The patient is held in the right head hanging position (Step 2) for 20 to 30 seconds, and then in Step 3 the head is turned 90 degrees toward the unaffected side. Step 3 is held for 20 to 30 seconds before turning the head another 90 degrees (Step 4) so the head is nearly in the face-down position. Step 4 is held for 20 to 30 seconds, and then the patient is brought to the sitting up position. The movement of the otolith material within the labyrinth is depicted witheach step, showing how otoliths are moved from the semicircular canal to the vestibule. Although it is advisable for the examiner to guide the patient through these steps, it is the patient's head position that is the key to a successful treatment.

nystagmus in response to the Dix-Hallpike maneuver. One to 2 weeks after treatment, $50 \%$ of the treated group reported symptom resolution vs $19 \%$ in the sham group, an absolute difference of $31 \%(95 \%$ CI $0.06-0.56, p=0.02$; NNT $=$ 3.22). Using the absence of nystagmus after the Dix-Hallpike maneuver as an outcome measurement, an improvement was seen in $65 \%$ of treated patients vs $38 \%$ of sham patients, a $27 \%$ absolute difference $(95 \%$ CI $0.02-0.52$, $p=0.046$; NNT $=3.7$ ).

Another Class II study ${ }^{5}$ randomized 29 patients to a CRP and another 29 patients to no treatment. The diagnosis of posterior BPPV was based on observing nystagmus after the DixHallpike maneuver and a "complete neurotological examination." All patients were given a prescription for cinnarizine to use for vertigo. Over the next month, all patients were exam- ined at weekly intervals by a blinded observer. Patients with a positive Dix-Hallpike maneuver who were assigned to the treatment group underwent repeat CRP. A questionnaire was administered to patients with a negative DixHallpike maneuver.

At 1 week, $41 \%$ of treated patients were symptom free, vs $3 \%$ of untreated controls $(p=0.005$; NNT $=2.63)$. The Dix-Hallpike maneuver was negative in $75.9 \%$ of treated patients vs $48.2 \%$ of untreated controls, an absolute difference of $27.7 \%(95 \%$ CI $0.241-0.489, p=0.03$; NNT $=$ $3.68)$. At 2 weeks, $65 \%$ were symptom free in the treatment group vs $3 \%$ of controls $(p<0.005)$. At 3 weeks, $65 \%$ were symptom free vs $21 \%$ of the controls $(p=0.014)$. There were no significant differences at 4 weeks. The control group used cinnarizine more often (23 doses) than did the treatment group (5.8 doses, $p=0.001$ ).

The third study ${ }^{6}$ randomized 124 patients to a CRP, a Semont liberatory maneuver (figure 3), Brandt-Daroff exercises (figure e-2), habituation exercises, or a sham maneuver of slow neck rotation and flexion performed with the patient in a sitting position. The diagnosis for posterior canal BPPV was based on history and paroxysmal positional nystagmus in response to the Dix-Hallpike maneuver (figure 1). The median duration of symptoms was 4 months (range 10 days to 30 years). The outcome measure was an arbitrary patient-rated vertigo intensity and frequency scale of 1 to 10 (10 being the most severe or frequent), recorded by a blinded observer.

The treatment effect in this study is difficult to quantify because the results are expressed in the form of regression curves, rather than as discrete values. At 90 days after treatment, vertigo frequency was reportedly "significantly reduced" in both CRP- and Semont maneuver-treated patients. Both treatment maneuvers were superior to the sham maneuver (CRP, $p=0.021$; Semont maneuver, $p=0.010$ ) for vertigo intensity. The vertigo scores were not significantly different between the CRP and Semont maneuver. There was significantly less frequent vertigo in those treated by either CRP or Semont maneuver compared with Brandt-Daroff exercises $(p=0.033)$.

The remaining randomized controlled trials were graded as Class IV because they did not clearly state whether the outcomes were obtained in a blinded and independent manner ${ }^{8-15}$ or because of important baseline differences between study and control groups. ${ }^{16}$

The literature search also yielded four metaanalyses and one systematic review. All four 
Figure 3 Semont maneuver for right-sided benign paroxysmal positional vertigo

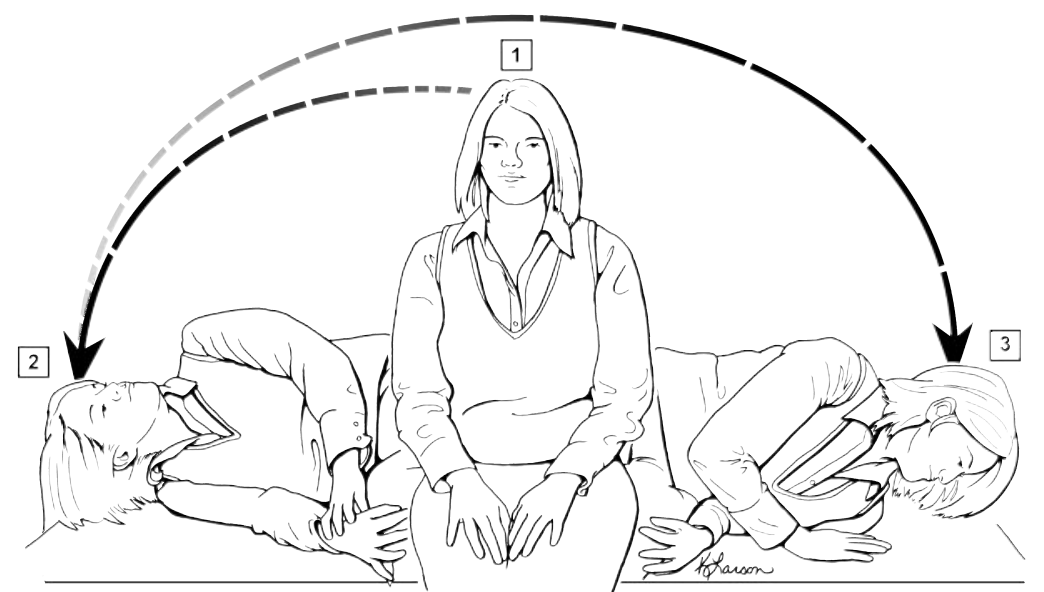

While sitting up in Step 1, the patient's head is turned 45 degrees toward the left side, and then the patient is rapidly moved to the side-lying position as depicted in Step 2. This position is held for 30 seconds or so, and then the patient is rapidly taken to the opposite side-lying position without pausing in the sitting position or changing the head position relative to the shoulder. This is in contrast to the Brandt-Daroff exercises that entail pausing in the sitting position and turning the head with body position changes.

meta-analyses ${ }^{17-20}$ concluded that CRP and Semont maneuver have significantly greater efficacy than no treatment in BPPV. All references included in these four meta-analyses were reviewed individually for this practice parameter.

In all these studies, complications of nausea and vomiting, fainting, or conversion to horizontal canal BPPV occurred in $12 \%$ of patients. In a retrospective study of 85 patients treated with a CRP, ${ }^{21} 6 \%$ developed a conversion to either horizontal canal BPPV or anterior canal BPPV.

Semont maneuver for BPPV. One Class II study ${ }^{6}$ showed that patients treated with Semont maneuver were "significantly" improved compared with those treated with a sham maneuver. A Class III study $^{22}$ randomized 156 patients to Semont maneuver, medical therapy (flunarizine $10 \mathrm{mg} / \mathrm{day}$ for 60 days), or no treatment. At 6-month followup, $94.2 \%$ of patients treated with Semont maneuver reported symptom resolution, vs $57.7 \%$ of patients treated with flunarizine and $34.6 \%$ of patients who received no treatment.

A Class IV study ${ }^{23}$ comparing Semont maneuver and a CRP either with or without posttreatment instructions found success rates for all groups ranging from $88 \%$ to $96 \%$, with no differences between groups. Another Class IV study ${ }^{24}$ compared patients randomized to treatment with CRP, Semont maneuver, or Brandt-Daroff exercises. Symptom resolution among those treated with either CRP or Semont maneuver at 1 week was the same $(74 \%$ vs $71 \% ; 24 \%$ for BrandtDaroff exercises). At 3-month follow-up, $93 \%$ of patients treated with CRP were asymptomatic vs
$77 \%$ of those treated with Semont maneuver $(p=$ $0.027) ; 62 \%$ of patients treated with BrandtDaroff exercises were asymptomatic at 3 months.

Conclusion. Two Class I studies and three Class II studies have demonstrated a short-term (1 day to 4 weeks) resolution of symptoms in patients treated with the CRP, with NNT ranging from 1.43 to 3.7. The Semont maneuver is possibly more effective than no treatment (Class III), a sham treatment (Class II), or Brandt-Daroff exercises (Class IV) as treatment for posterior canal BPPV. Two Class IV studies comparing CRP with Semont maneuver have produced conflicting results; one showed no difference between groups, and the other showed a lower recurrence rate in patients undergoing CRP.

Recommendation (appendix e-3). Canalith repositioning procedure is established as an effective and safe therapy that should be offered to patients of all ages with posterior semicircular canal BPPV (Level A recommendation). The Semont maneuver is possibly effective for BPPV but receives only a Level C recommendation based on a single Class II study. Although many experts believe that the Semont maneuver is as effective as canalith repositioning maneuver, based on currently published articles the Semont maneuver can only be classified as "possibly effective." There is insufficient evidence to establish the relative efficacy of the Semont maneuver to CRP (Level U).

Question 2: Which maneuvers are the most effective treatments for horizontal canal and anterior canal BPPV? Horizontal canal BPPV. Horizontal canal BPPV accounts for $10 \%$ to $17 \%$ of BPPV,,$^{25-29}$ though some reports have been even higher. ${ }^{30,31}$ The nystagmus of horizontal canal BPPV is horizontal and changes direction when the head is turned to the right or left while supine (directionchanging paroxysmal positional nystagmus). The direction-changing positional nystagmus may be either geotropic or apogeotropic. ${ }^{31}$ The geotropic form, which is thought to result from free-moving otoconial debris in the long arm of the semicircular duct, is generally more responsive to treatment. The apogeotropic form is likely due to otoconial material in the short arm of the canal or attached to the cupula (cupulolithiasis). ${ }^{24,32}$ Hence, one seeks to convert the more treatment-resistant apogeotropic to the more treatment-responsive geotropic nystagmus form of horizontal canal BPPV. ${ }^{32,33}$

The nystagmus and vertigo of horizontal canal BPPV may be provoked by the Dix-Hallpike maneuver but are more reliably induced by the supine head roll test or so-called Pagnini-McClure maneuver (figure 4). ${ }^{34-36}$ The methods used to de- 
Figure 4 Supine roll test (Pagnini-McClure maneuver) to detect horizontal canal benign paroxysmal positional vertigo (BPPV)
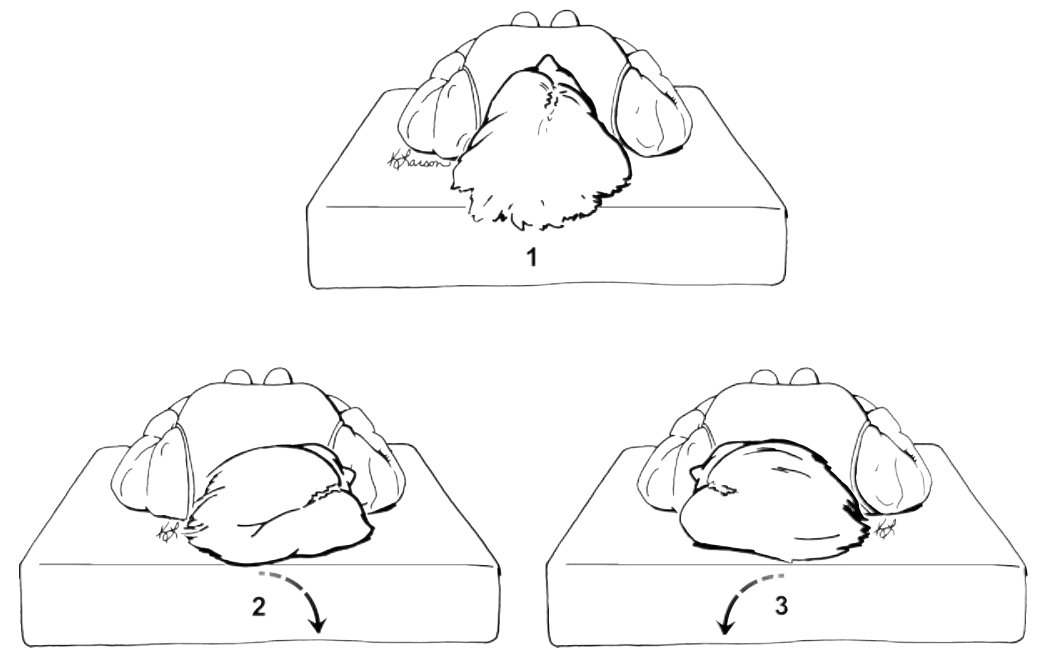

The patient may be taken from sitting to straight supine position (1). The head is turned to the right side (2) with observation of nystagmus and then turned back to face up (1). Then the head is turned to the left side (3). The side with the most prominent nystagmus is taken to be the affected horizontal semicircular canal. The direction of nystagmus in each position determines whether the horizontal canal BPPV is of the geotropic or apogeotropic type.

termine the affected side in horizontal canal BPPV are described elsewhere. ${ }^{30,37,38, \mathrm{el} 1} \mathrm{CRP}$ or modified Epley maneuvers are usually ineffective for horizontal canal BPPV, ${ }^{21,34}$ so a number of alternative maneuvers have been devised.

Variations of the roll maneuver (Lempert maneuver or barbecue roll maneuver) (figure 5) are

Figure 5 Lempert roll maneuver for right-sided horizontal canal benign paroxysmal positional vertigo (BPPV)

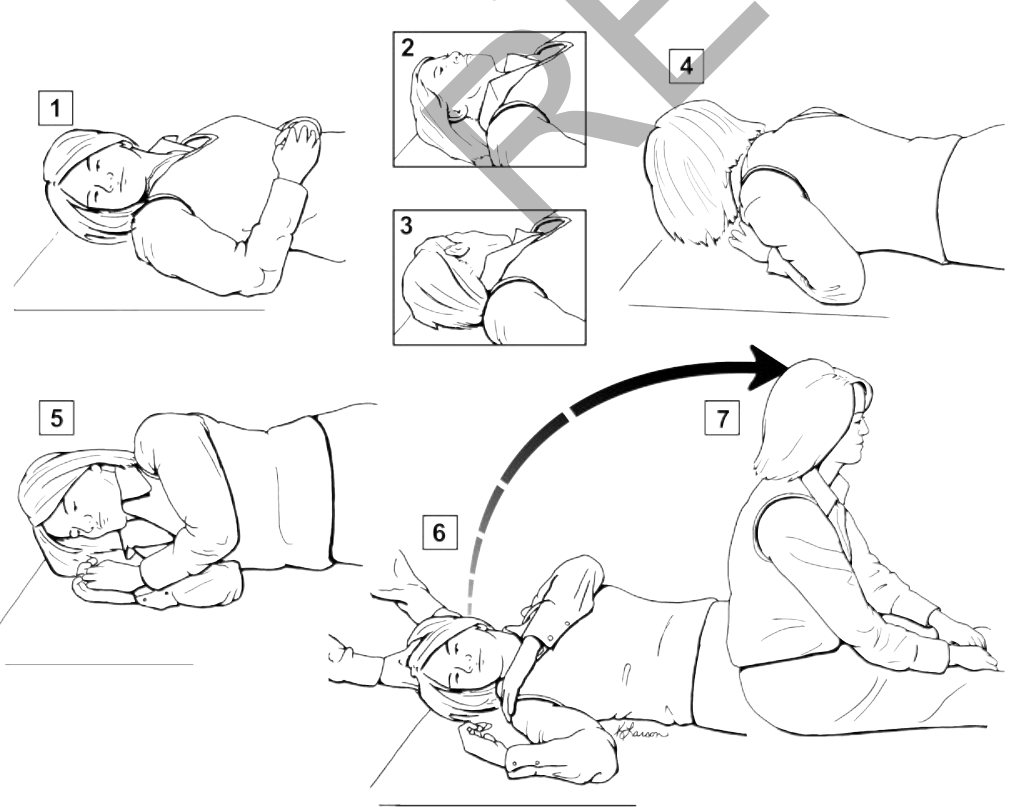

When it is determined to be horizontal canal BPPV affecting the right side, the patient is taken through a series of step-wise 90-degree turns away from the affected side in Steps 1 through 5, holding each position for 10 to 30 seconds. From Step 5, the patient positions his or her body to the back (6) in preparation for the rapid and simultaneous movement from the supine face up to the sitting position (7). the most widely published treatments for horizontal canal BPPV. $25,26,29,31,32,34,36,38, \mathrm{e} 1, \mathrm{e} 2$ Success in treatment, based on all Class IV studies, is probably $<75 \%{ }^{32, \text { e2 }}$ but ranges from approximately $50 \%$ to nearly $100 \%$. However, the studies used differing and sometimes unclear endpoints, and many lacked control groups to allow comparison between the treatment and the natural rate of resolution of this condition.

The Gufoni maneuver is another technique that has been reported as effective in treating horizontal canal BPPV ${ }^{\mathrm{e} 3}$ (figure e-3, A and B). Several studies, all Class IV, have reported success using this or a similar maneuver for horizontal canal BPPV for both the geotropic and apogeotropic nystagmus forms. ${ }^{32,33,38, e 4}$ Similarly, the Vannucchi-Asprella liberatory maneuver may be effective, but there is only limited Class IV data supporting its use. ${ }^{38, e 5, e 6}$ Casani et al..$^{32}$ and Appiani et al. ${ }^{33}$ review other techniques used with success in the treatment of both the geotropic and apogeotropic forms of horizontal canal BPPV.

Another treatment reported as effective $\mathrm{e}^{30,32,36,22, \mathrm{e} 7}$ is referred to as forced prolonged positioning. With this method, the patient lies down laterally to the affected side, and the head is then turned 45 degrees toward the ground and maintained in that position for 12 hours before the patient is returned to the starting position. Some authors advocate this technique for refractory horizontal canal BPPV., ${ }^{32, e 3}$ Using this approach, one Class IV study reported remission rates of $75 \%$ to $90 \% .32$

Anterior canal BPPV. Anterior canal BPPV is usually transitory and most often is the result of "canal switch" that occurs in the course of treating other more common forms of BPPV. ${ }^{21}$

We identified only two studies specifically addressing the treatment of anterior canal BPPV; both were Class IV studies. ${ }^{\text {es,e9 }}$ Success rates were between $92 \%$ and $97 \%$, though there were no controls to determine whether this represents an improvement over the natural history of this frequently self-resolving form of BPPV.

Conclusion. Based on Class IV studies, variations of the Lempert supine roll maneuver, the Gufoni method, or forced prolonged positioning seem moderately effective for horizontal canal BPPV. Two uncontrolled Class IV studies report high response rates to maneuvers for anterior canal BPPV.

Recommendation: None (Level U).

Question 3: Are postmaneuver activity restrictions necessary after canalith repositioning procedure? In one Class I study ${ }^{2}$ and one Class II ${ }^{4}$ study demonstrating the benefit of CRP, patients wore a cervical collar for 48 hours and avoided sleeping on the 
affected side for 1 week. One Class I study ${ }^{3}$ and two Class II studies ${ }^{5,6}$ that demonstrated the benefit of CRP used no post-treatment restrictions or instructions. These studies were not designed to determine whether such restrictions affect treatment success; however, there seems to be little difference in the rate of treatment success whether or not restrictions were included.

Six Class IV studies comparing CRP with and without post-treatment activity restriction were identified. ${ }^{23, \text { e10-e14 }}$ Five studies ${ }^{23, \text { e10-e13 }}$ showed no added benefit from post-treatment activity restriction or positions. Only one study showed a minimal benefit in patients with post-activity restrictions, as measured by the number of maneuvers required to produce a negative Dix-Hallpike maneuver. ${ }^{\text {e14 }}$

Conclusion and recommendation. Five Class IV studies support the omission of post-treatment activity restrictions; one study supports the use of post-treatment restrictions. There is insufficient evidence to determine the efficacy of postmaneuver restrictions in patients treated with CRP (Level U).

Question 4: Is it necessary to include mastoid vibration with repositioning maneuvers? Mastoid vibration was included in the original Epley repositioning maneuver. One Class II study, ${ }^{\mathrm{e} 15}$ comparing patients with posterior canal BPPV treated by "appropriate canalith repositioning maneuvers," performed with and without vibration, showed no difference in immediate symptom resolution or relapse rate between groups.

A Class III study ${ }^{\mathrm{e} 16}$ compared patients treated by CRP with and without mastoid vibration. There was no difference in symptom relief between the groups at 4 to 6 weeks ( $p=0.68$ ).

Two Class IV studies ${ }^{\mathrm{e} 17, \mathrm{e} 18}$ showed no difference in the rate of symptom resolution between patients treated by a CRP with or without mastoid vibration. A third Class IV study ${ }^{9}$ reported that of patients treated by a CRP with vibration, $92 \%$ were "improved," vs $60 \%$ improvement with CRP alone.

Conclusion and recommendation. One Class II, one Class III, and two Class IV studies showed no added benefit when mastoid vibration was added to a CRP as treatment for posterior canal BPPV. Mastoid oscillation is probably of no added benefit to patients treated with CRP for posterior canal BPPV (Level C recommendation).

Question 5: What is the efficacy of Brandt-Daroff exercises, habituation exercises, or patient selfadministered treatments for BPPV? A Class II study that randomized patients to a CRP, a "liberatory maneuver," Brandt-Daroff exercises, "habituation exercises," or a sham treatment found that patients treated with habituation exercises did no better than those treated with a sham procedure. ${ }^{6}$ Patients treated with Brandt-Daroff exercises did worse than those treated with CRP or liberatory maneuvers but were not compared with sham-treated patients.

A Class IV study ${ }^{24}$ compared Brandt-Daroff exercises, performed three times daily, with the Semont maneuver or CRP. Patients treated with maneuvers were pretreated with diazepam and given postmaneuver activity restrictions; patients treated with Brandt-Daroff exercises were not. Compliance with the exercises was not recorded. At 1-week follow-up, $24 \%$ of patients treated with Brandt-Daroff exercises were symptom free, vs $74 \%$ of those treated with the Semont maneuver or CRP. Given the limitations of the study, its validity is questionable.

Three Class IV studies investigated the efficacy of patient-administered treatment for BPPV using various techniques. One study found $88 \%$ improvement of BPPV when treated with CRP and home CRP compared with $69 \%$ improvement in those only treated with CRP once. ${ }^{119}$ Another study reported improved resolution of nystagmus among patients that selfadministered CRP (64\% recovery) vs selfadministered Brandt-Daroff exercises (23\%). e $20^{20}$ The third study found that $95 \%$ had resolution of positional nystagmus 1 week after selftreatment with CRP vs $58 \%$ of self-treatment with a modified Semont maneuver. . $21^{21}$

Conclusion and recommendation. One Class II and one Class IV study suggest that Brandt-Daroff exercises or habituation exercises are less effective than CRP in the treatment of posterior canal BPPV. Self-administered Brandt-Daroff exercises or habituation exercises are less effective than CRP in the treatment of posterior canal BPPV (Level C). There is insufficient evidence to recommend or refute self-treatment using Semont maneuver or CRP for BPPV (Level U).

Question 6: What is the efficacy of medication treatments for BPPV? One Class III study ${ }^{\mathrm{e} 22}$ found no difference between lorazepam, $1 \mathrm{mg}$ three times daily; diazepam, $5 \mathrm{mg}$ three times daily; or placebo over the 4-week study period. Another Class III study ${ }^{21}$ found that flunarizine was more effective than no treatment but less effective than Semont maneuver in eliminating symptoms. There are no randomized controlled trials of meclizine 
or other drugs used for motion sickness in the treatment of BPPV.

Conclusion and recommendation. A single Class III study did not demonstrate that lorazepam or diazepam hastened resolution of symptoms in BPPV. A single Class III study demonstrated some benefit of flunarizine, a drug that is unavailable in the United States, in BPPV. There is no evidence to support a recommendation of any medication in the routine treatment for BPPV (Level U).

Question 7: What are the safety and efficacy of surgical treatments for posterior canal BPPV? All studies of surgical treatment for refractory BPPV are Class IV. The most common procedure is fenestration and occlusion of the posterior semicircular canal. Five studies, e23-e27 with a total of 86 patients undergoing canal occlusion, reported "complete relief" of BPPV symptoms in 85, as ascertained by the treating surgeon. Reported complications included a "mild" conductive hearing loss for 4 weeks or less, "mild" and "transient" unsteadiness in most patients, and a high frequency sensorineural hearing loss in 6 patients.

In a Class IV study of singular neurectomy as a treatment for intractable BPPV, 228 96.8\% were reported to have "complete relief"; severe sensorineural hearing loss occurred in $3.7 \%$ of patients.

Conclusion and recommendation. Six unblinded, retrospective Class IV studies report relief from symptoms of BPPV in nearly every patient undergoing posterior semicircular canal occlusion or singular neurectomy. Because the studies are Class IV, they do not provide sufficient evidence to recommend or refute posterior semicircular canal occlusion or singular neurectomy as treatment for BPPV (Level U).

RECOMMENDATIONS FOR FUTURE RESEARCH Class I studies are needed to clarify the best treatments for horizontal canal BPPV. Future studies on these topics should adhere to the Consolidated Standards of Reporting Trials (CONSORT) criteria using validated, clinically relevant outcomes.

PROGNOSIS AND RECURRENCE RATE The relapse rate and second recurrence rate of BPPV are not fully established. Short-term relapse rates range from $7 \%$ to nearly $23 \%$ within a year of treatment, but long-term recurrences may approach $50 \%$, depending on the age of the patient. ${ }^{\text {e29-e32 }}$

\section{DISCLOSURE}

The authors report the following disclosures: Dr. Fife has received research support from GlaxoSmithKline and esti- mates that $6 \%$ of his time is spent on canalith repositioning procedures. Dr. Iverson has nothing to disclose. Dr. Lempert estimates that $<5 \%$ of his time is spent on videooculography. Dr. Furman holds stock options in Neurokinetics, has received research support from Merck, has served as an expert witness on vestibular function, and estimates that $1 \%$ of his time is spent on the Epley maneuver. Dr. Baloh estimates $5 \%$ of his time is spent on ENG. Dr. Tusa estimates that $5 \%$ of his time is spent on quantified positional testing. Dr. Hain estimates that $5 \%$ of his time is spent on ENG and $5 \%$ on VEMP. Dr. Herdman received research support from VAMC and served as an expert witness on the Hallpike-Dix maneuver. Dr. Morrow has received honoraria from BiogenIdec and has served as an expert witness and consultant on medico-legal proceedings. Dr. Gronseth has received speaker honoraria from Pfizer, GlaxoSmithKline, and Boehringer Ingelheim and served on the IDMC Committee of Ortho-McNeil.

\section{DISCLAIMER}

This statement is provided as an educational service of the American Academy of Neurology. It is based on an assessment of current scientific and clinical information. It is not intended to include all possible proper methods of care for a particular neurologic problem or all legitimate criteria for choosing to use a specific procedure. Neither is it intended to exclude any reasonable alternative methodologies. The American Academy of Neurology recognizes that specific patient care decisions are the prerogative of the patient and the physician caring for the patient, based on all of the circumstances involved.

Received August 1, 2007. Accepted in final form February 23, 2008 .

\section{REFERENCES}

1. von Brevern M, Radtke A, Lezius F, et al. Epidemiology of benign paroxysmal positional vertigo: a population based study. J Neurol Neurosurg Psychiatr 2007; 78:710-715.

2. Lynn S, Pool A, Rose D, Brey R, Suman V. Randomized trial of the canalith repositioning procedure. Otolaryngol Head Neck Surg 1995;113:712-720.

3. von Brevern M, Seelig T, Radtke A, Tiel-Wilck K, Neuhauser H. Long-term efficacy of Epley's manoeuvre: a double-blind randomized trial. J Neurol Neurosurg Psychiatr 2006;77:980-982.

4. Froehling DA, Bowen JM, Mohr DN, et al. The canalith repositioning procedure for the treatment of benign paroxysmal positional vertigo: a randomized controlled trial. Mayo Clin Proc 2000;75:695-700.

5. Yimtae K, Srirompotong S, Srirompotong S, Sae-Seaw P. A randomized trial of the canalith repositioning procedure. Laryngoscope 2003;113:828-832.

6. Cohen HS, Kimball KT. Effectiveness of treatments for benign paroxysmal positional vertigo of the posterior canal. Otol Neurotol 2005;26:1034-1040.

7. Schulz KF, Grimes DA. Allocation concealment in randomised trials: defending against deciphering. Lancet 2002;359:614-618. 
8. Sherman D, Massoud EA. Treatment outcomes of benign paroxysmal positional vertigo. J Otolaryngol 2001;30:295-299.

9. Li JC. Mastoid oscillation: a critical factor for success in canalith repositioning procedure. Otolaryngol Head Neck Surg 1995;112:670-675.

10. Blakley BW. A randomized, controlled assessment of the canalith repositioning maneuver. Otolaryngol Head Neck Surg 1994;110:391-396.

11. Lempert T, Wolsley C, Davies R, et al. Three hundred sixty-degree rotation of the posterior semicircular canal for treatment of benign positional vertigo: a placebo-controlled trial. Neurology 1997;49:729-733.

12. Wolf M, Hertanu T, Novikov I, Kronenberg J. Epley's manoeuvre for benign paroxysmal positional vertigo: a prospective study. Clin Otolaryngol 1999;24:43-46.

13. Asawavichianginda $\mathrm{S}$, Isipradit $\mathrm{P}$, Snidvongs $\mathrm{K}$, et al. Canalith repositioning for benign paroxysmal positional vertigo: a randomized, controlled trial. Ear Nose Throat J 2000;79:732-734.

14. Angeli SI, Hawley R, Gomez O. Systematic approach to benign paroxysmal positional vertigo in the elderly. Otolaryngol Head Neck Surg 2003;128:719-725.

15. Sridhar S, Panda N. Particle repositioning manoeuvre in benign paroxysmal positional vertigo: is it really safe? J Otolaryngol 2005;34:41-45.

16. Chang AK, Schoeman G, Hill M. A randomized clinical trial to assess the efficacy of the Epley maneuver in the treatment of acute benign positional vertigo. Acad Emerg Med 2004;11:918-924.

17. Lopez-Escamaez J, Gonzalez-Sanchez M, Salinero J Meta-analysis of the treatment of benign paroxysmal positional vertigo by Epley and Semont maneuvers. Acta Otorrinolaringol Esp 1999;50:366-370.

18. Woodworth BA, Gillespie MB, Lambert PR. The canalith repositioning procedure for benign positional vertigo: a meta-analysis. Laryngoscope 2004;114:1143-1146.

19. Teixeira LJ, Machado JN. Maneuvers for the treatment of benign positional paroxysmal vertigo: a systematic review. Rev Bras Otorrinolaringol (Engl Ed) 2006; $72: 130-139$.

20. Hilton M, Pinder D. The Epley manoeuvre for benign paroxysmal positional vertigo: a systematic review. Clin Otolaryngol Allied Sci 2002;27:440-445.

21. Herdman SJ, Tusa RJ. Complications of the canalith repositioning procedure. Arch Otolaryngol Head Neck Surg 1996;122:281-286.

22. Salvinelli F, Casale M, Trivelli M, et al. Benign paroxysmal positional vertigo: a comparative prospective study on the efficacy of Semont's maneuver and no treatment strategy. Clin Ter 2003;154:7-11.

23. Massoud EA, Ireland DJ. Post-treatment instructions in the nonsurgical management of benign paroxysmal positional vertigo. J Otolaryngol 1996;25:121-125.
24. Soto Varela A, Bartual Magro J, Santos Perez S, et al. Benign paroxysmal vertigo: a comparative prospective study of the efficacy of Brandt and Daroff exercises, Semont and Epley maneuver. Rev Laryngol Otol Rhinol (Bord) 2001;122:179-183.

25. White JA, Coale KD, Catalano PJ, Oas JG. Diagnosis and management of horizontal semicircular canal benign paroxysmal positional vertigo. Otolaryngol Head Neck Surg 2005;133:278-284.

26. Prokopakis EP, Chimona T, Tsagournisakis M, et al. Benign paroxysmal positional vertigo: 10 -year experience in treating 592 patients with canalith repositioning procedure. Laryngoscope 2005;115:16671671.

27. Caruso G, Nuti D. Epidemiological data from 2270 PPV patients. Audiological Med 2005;3:7-11.

28. Leopardi G, Chiarella G, Serafini G, et al. Paroxysmal positional vertigo: short- and long-term clinical and methodological analyses of 794 patients. Acta Otolaryngol Ital 2003;23:155-160.

29. Fife TD. Recognition and management of horizontal canal benign positional vertigo. Am J Otol 1998;19: 345-351.

30. Koo JW, Moon IJ, Shim WS, Moon SY, Kim JS. Value of lying-down nystagmus in the lateralization of horizontal semicircular canal benign paroxysmal positional vertigo. Otol Neurol 2006;27:367-371.

31. Nuti D, Agus G, Barbieri M-T, Passali D. The management of horizontal-canal paroxysmal positional vertigo. Acta Otolaryngol 1998;118:455-460.

32. Casani AP, Vannucchi G, Fattori B, Berrettini S. The treatment of horizontal canal positional vertigo: our experience in 66 cases. Laryngoscope 2002;112:172178.

33. Appiani GC, Catania G, Gagliardi M, Cuiuli G. Repositioning maneuver for the treatment of the apogeotropic variant of horizontal canal benign paroxysmal positional vertigo. Otol Neurotol 2005;26:257-260.

34. Lempert T, Tiel-Wilck K. A positional maneuver for treatment of horizontal-canal benign positional vertigo. Laryngoscope 1996;106:476-478.

35. McClure JA. Horizontal canal BPV. J Otolaryngol 1985;14:30-35.

36. Appiani GC, Gagliardi M, Magliulo G. Physical treatment of horizontal canal benign positional vertigo. Eur Arch Otorhinolaryngol 1997;254:326-328.

37. Han BI, Oh HJ, Kim JS. Nystagmus while recumbent in horizontal canal benign paroxysmal positional vertigo. Neurology 2006;66:706-710.

38. Asprella Libonati G. Diagnostic and treatment strategy of the lateral semicircular canal canalolithiasis. Acta Otorhinolaryngol Ital 2005;25:277-283. 


\title{
Neurology
}

\author{
Practice Parameter: Therapies for benign paroxysmal positional vertigo (an \\ evidence-based review): [RETIRED]: Report of the Quality Standards Subcommittee of \\ the American Academy of Neurology \\ T. D. Fife, D. J. Iverson, T. Lempert, et al. \\ Neurology 2008;70;2067-2074 \\ DOI 10.1212/01.wnl.0000313378.77444.ac
}

This information is current as of May 27, 2008

Updated Information \& Services

Supplementary Material

\section{References}

Citations

Subspecialty Collections

Permissions \& Licensing

Reprints including high resolution figures, can be found at: http://n.neurology.org/content/70/22/2067.full

Supplementary material can be found at: http://n.neurology.org/content/suppl/2008/05/24/70.22.2067.DC1 http://n.neurology.org/content/suppl/2008/11/16/70.22.2067.DC3 http://n.neurology.org/content/suppl/2008/06/09/70.22.2067.DC2

This article cites 38 articles, 4 of which you can access for free at: http://n.neurology.org/content/70/22/2067.full\#ref-list-1

This article has been cited by 13 HighWire-hosted articles: http://n.neurology.org/content/70/22/2067.full\#\#otherarticles

This article, along with others on similar topics, appears in the following collection(s):

\section{All Neurotology}

http://n.neurology.org/cgi/collection/all_neurotology

Nystagmus

http://n.neurology.org/cgi/collection/nystagmus

Vertigo

http://n.neurology.org/cgi/collection/vertigo

Information about reproducing this article in parts (figures,tables) or in its entirety can be found online at:

http://www.neurology.org/about/about_the_journal\#permissions

Information about ordering reprints can be found online:

http://n.neurology.org/subscribers/advertise

Neurology ${ }^{\circledR}$ is the official journal of the American Academy of Neurology. Published continuously since 1951, it is now a weekly with 48 issues per year. Copyright. All rights reserved. Print ISSN: 0028-3878. Online ISSN: 1526-632X.

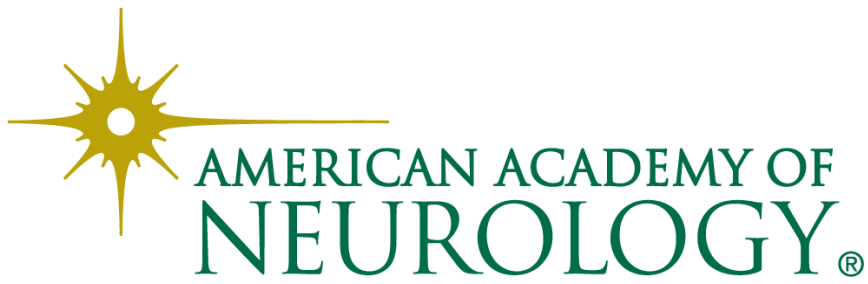

